\title{
Gazette
}

\section{Minutes of the Spring 2020 Council Meeting}

\author{
Saturday, April 4, 2020
}

\section{MEMBERS PRESENT}

President: Paula D. McClain (Duke University); Past-President: Rogers Smith (University of Pennsylvania); President-Elect: Janet Box-Steffensmeier (Ohio State University); Vice Presidents: Kerstin Hamann (University of Central Florida), Leonard Wantchekon (Princeton University), Melissa Williams (University of Toronto); Treasurer: Thomas Pepinsky (Cornell University)

Council Members: Ben Ansell (University of Oxford); Adam Berinksy (Massachusetts Institute of Technology); Erik Bleich (Middlebury College); Ann O'M. Bowman (Texas A\&M University); Joseph Carens (University of Toronto); Alexandra Filindra (University of Illinois at Chicago); Lisa Garcia-Bedolla (University of California, Berkeley); Rebecca Gill (University of Nevada, Las Vegas); Lilly Goren (Carrol University); Julia Jordan-Zachery, (University of North Carolina at Charlotte); Sooyeon Kim (National University of Singapore); Matthew Kocher (Johns Hopkins University); David Leal (University of Texas at Austin); Suzanna Linn (Pennsylvania State University); Lori Marso (Union College); Melanye Price (Prairie View A\&M University); Erin Richards (Cascadia College); Alberto Simpser (Instituto Tecnológico Autónomo de México); Valeria SinclairChapman (Purdue University); Laura Sjoberg (University of Florida); Charles Smith (University of California, Irvine); Rocio Titiunik (Princeton University); Lisa Wedeen (University of Chicago)

APSA Staff: Steven Rathgeb Smith, Betsy Super, Dan Gibson, Kimberley Mealy, Nathan Bader, Larry Burner, Amanda Grigg, Jon Gurstelle, Casey Harrigan, Meghan McConaughey, Erin McGrath, Abby Paulson, Jason Sapia, Tanya Schwarz, Jasmine Scott, Ashley Vande Bunte

Other Attendees: Scott Desposato, co-chair of Human Subjects Review Committee; Wendy Pearlman, chair of the Perspectives Editor Review Committee;
Robert Lieberman, chair of the Smith Presidential Task Force.

\section{INTRODUCTION}

APSA President Paula McClain calls the 2020 APSA Spring Council Meeting to order.

\section{CONSENT AGENDA}

McClain introduces the August 2019 Council meeting minutes for Council approval. R. Smith moves to approve the minutes; the motion is seconded and passes unanimously. McClain introduces the proposed APSR editorial board changes for Council approval. Sjoberg moves to approve the APSR editorial board changes; Linn seconds. Goren and Richards note that it would be good to see more representation from schools that are not elite institutions. Berinksy asks for a lab experimentalist to be included on the editorial board. SinclairChapman replies that concerns should be directed to the editorial board organizing team. The Council votes and the motion is approved.

\section{MCCLAIN TASK FORCE UPDATE}

McClain introduces an update on the McClain Presidential Task Force on Examining Issues and Mechanisms of Systemic Inequality in the Discipline. Working groups for the task force will be chaired by: Niambi Carter, Howard University; Cathy Cohen, University of Chicago; John Garcia, University of Michigan; and Carol Mershon, University of Virginia. Garcia will lead the working group on Citation Patterns and Inequities. Carter will lead the working group on Graduate Training and Graduate Student Experiences. Cohen will lead the working group on Tenure and Promotion Standards. Mershon will lead the working group on Climate and Context. McClain reports that the target completion date for the McClain Task Force is September 2021. Mealy notes that McClain will provide updates through September 2021.

\section{RBSI UPDATE}

McClain introduces an update on the status of the 2020 Ralph Bunche Summer Institute. McClain reports that the Ralph Bunche Summer Institute at Duke University has been cancelled for 2020. Duke University has cancelled all summer programming due to COVID-19. Mealy notes that the 19 admitted students in the 2020 class will be consulted regarding their interest in participating in alternative programming. Mealy reports that options for alternative programming include but are not limited to incorporating 2020 participants into RBSI and MFP alumni calls, facilitating research calls, and setting up one-on-one mentors. Berinsky asks if there is an option for conducting the Graduate School Recruiting Fair in a virtual manner. Mealy replies that the Graduate School Information Fair will occur at the 2020 annual meeting.

\section{TREASURER'S REPORT}

Treasurer Thomas Pepinsky introduces the treasurer's report to update the Council on the association's financial position. Pepinsky reports that APSA continues to operate in sound financial shape, even in the midst of unprecedented financial volatility. As of the most recent check, the total fair market value of all APSA's investments was $\$ 35.7$ million, with the most significant investment groups being the Congressional Fellowship Program trust portfolio which totaled \$16.8 million and the Trust and Development portfolio which totaled $\$ 16.9$ million. Due to the financial volatility caused by COVID-19, APSA investments are down. However, APSA is projected to be in line for the year with budgeted operating revenues and expenses. The coming years will be planned with care and a mind to the increased uncertainty expected in many of APSA's traditional revenue streams.

\section{EXECUTIVE DIRECTOR'S REPORT}

APSA Executive Director Steven Rathgeb Smith introduces updates on association programming and operations to provide information to the Council. S. Smith begins 
the discussion by providing an update on the association's response to the coronavirus, including communication plans, working with Cambridge University Press, the 2020 annual meeting, member services, and APSA Educate. He reports that APSA has created a webpage with resources related to COVID-19 and shifting to online teaching, all APSA members can enjoy full access to the Cambridge digital library, APSA has released a statement regarding accommodations for tenure and promotion, compiled a list of online teaching resources, adjusted research grant cycles, and pushed updates on APSA Connect. He further notes that APSA staff are teleworking.

Pepinsky asks if APSA can track institutional responses around accommodations for tenure and promotion. Linn expresses concern that the costs of the pandemic will be disproportionately born by graduate students and faculty at smaller and public universities as opposed to larger or private universities. Kocher remarks that largescale job losses among term faculty are a possibility. Garcia-Bedolla asks if APSA can consider a post-doctoral program due to the hiring freezes around the nation to provide a transitional period for some students. S. Smith responds that the possibility of a post-doctoral program could merit further discussion. Box-Steffensmeier notes that APSA can encourage non-academic routes in government, nonprofits, and industry. Richards expresses that many professors are adjusting their teaching modalities to reflect an online format. She notes that the discipline will increasingly use virtual teaching modalities and expresses interest in APSA providing best practices and professional development for online teaching. Wantchekon notes that the pandemic is disrupting fieldwork for both faculty and graduate students.

S. Smith discusses the Cambridge publishing response. He reports that Cambridge stopped all conference attendance through August 31, 2020, and halted all print publications due to disruptions in their global supply chain. S. Smith then discusses the annual meeting. He reports that APSA is actively researching virtual options and hybrid options for the annual meeting but notes that it is difficult for a conference of APSA's size to be conducted virtually. S. Smith reports that APSA's hotel contracts contain a force majeure clause and that APSA has a communicable disease rider on their event insurance that covers lost revenue. S. Smith notes that APSA does not have a specific deadline to decide about the status of the annual meeting but will continue to consider the circumstances and consult with Council.

Pepinsky notes that safety and public health are priorities, however, the annual meeting is important for connecting people to jobs, which he expects will be particularly important. Council members express concern that many people will not attend the meeting due to travel restrictions, institutional budgets, international visas or comfort with travel. S. Smith replies that APSA is exploring all possibilities of how to hold the annual meeting and professional development opportunities considering the current environment. Ansell asks about the percentage of international attendees at the annual meeting. S. Smith replies that approximately $20 \%$ of attendees come from outside of the United States. JordanZachery suggests that alternative conference models and structures may better serve both APSA membership and the discipline in the face of changes to the academy as a result of COVID-19. Williams asks about the technical and logistical considerations necessary to determine the format of the meeting and a timeline associated with those considerations. S. Smith and Super note that member views and vendor needs are being considered along with the current environment. Bleich underscores the importance of communicating to members that APSA understands the uncertainty of the current situation. Price and Pepinsky ask about the hiring process, jobs, and professional development piece of the annual meeting. S. Smith replies that APSA is expanding professional development opportunities and non-academic positions on eJobs. McClain notes that she would be willing to create a presidential task force on the discipline's response to the coronavirus. Super notes that a vote on the creation of a task force can be done at the conclusion of the meeting.

S. Smith introduces a discussion about APSA Educate, which is an online portal for teaching and learning resources. He notes that the launch date for APSA Educate was to coincide with the annual meeting, but in response to the pandemic a beta version with all the key features has been accelerated and is active now. Grigg reports that APSA Educate features resources for faculty such as syllabi and lecture slides. She also notes that educators can submit resources. Richards asks about accessibility and copyright for materials posted to the site. Grigg replies that access is open to all persons with an APSA account. Grigg continues that when submitting a resource, a creative commons license is required, but there are various options allowing for differing levels of commercial reuse.

S. Smith opens a discussion on the APSA Doctoral Dissertation Research Improvement Grant (DDRIG) program. He notes that the DDRIG program has been administered by the National Science Foundation (NSF). APSA was originally approached in 2012 with the possibility of taking over control of the program with NSF funding. In 2019, APSA was encouraged by NSF to apply to take over the grant program as NSF pivots to focus on larger grant programs. APSA was formally awarded a grant to administer the DDRIG program in March 2020. McConaughey will serve as program director. Jessica Keefe will serve as program manager. S. Smith and Mealy will provide support. APSA has signed a new contract for an online submission system to support the application and review system for the DDRIG program as well as APSA's other grants and fellowship programs. S. Smith underscores that the DDRIG program is an APSA program supported by an NSF grant. McConaughey notes that the application deadline for 2020 will be June 15 , which is the same deadline as under the NSF program. Filindra asks who will appoint reviewers. Wedeen asks for a commitment to methodological diversity from the reviewers. S. Smith notes that he, as the person ultimately responsible for the grant, will appoint reviewers and that methodological and other forms diversity will be an important consideration. He notes that he is open to consultation on appointment of review panel members. Garcia-Bedolla asks if APSA itself may consider adding some funds for the additional grants due to the possibility of graduate funding declining. S. Smith notes that this suggestion will be considered.

S. Smith opens a discussion about ongoing programmatic efforts. He begins by discussing the Teaching and Learning Conference that was held in Albuquerque, New Mexico in February with 274 attendees. S. Smith then discusses the launch of the Raise the Vote campaign. Raise the Vote was launched in November 2019. Schwarz notes that students and faculty are encouraged to submit research related to political participation.

S. Smith opens a discussion on financial and strategic planning with a focus on 
the impacts of the pandemic on APSA. He notes that revenue from the annual meeting has risen as a percentage of total APSA revenue in the past 10-15 years. The impact of the pandemic on membership, eJobs, and their revenues for APSA is also uncertain. $S$. Smith reports that investment income has been affected by the volatility in the stock market. He notes that the pandemic may also affect APSA's rental income through tenants facing financial losses. S. Smith reports that APSA has a publications contract with Cambridge that will ensure that publishing revenues remain stable in the short-term. The contract will be reset in 2021. He notes that APSA may see less revenue from Cambridge from 2021-2026 after the contract terms are reevaluated. He notes that Cambridge has temporarily ceased production of APSA's print journals. S. Smith reports that APSA is planning to apply for financial assistance through the CARES Act and is working closely with APSA's legal counsel on the situation.

S. Smith notes that APSA is also looking at the long-term effects of the pandemic on members, institutions, and the discipline. As such, APSA is revisiting the strategic plan. He notes that the pandemic will put pressure for more open access, accelerate the decline of print journals, increase online and hybrid teaching modalities, decrease conference travel, and may highlight inequities among members and institutions in terms of access to resources as well as how APSA addresses those inequities. S. Smith expresses that APSA is rethinking the value proposition for members and how to better address the needs and wants of the membership.

\section{HUMAN SUBJECTS RESEARCH} REVIEW COMMITTEE REPORT

S. Smith introduces the report of the Human Subjects Research Review Committee. He welcomes Scott Desposato, co-chair of the Human Subjects Research Review Committee. Desposato notes that the principles proposed by the committee are not rules but principles to promote discussion and transparency. He reports that the principles are a framework that has the capacity to promote dialogue among political scientists about the use and role of human subjects. The Council thanks the committee for their revisions and thoughtful discussion. Sjoberg asks if the committee will be available to help interpret the guidelines. Desposato replies that the committee will not be available in that capacity. He notes that the guidelines are a starting point from which the discipline must interpret and engage in going forward. Kocher asks for more information on the discussion of the relationship between political science research and legal systems. Desposato notes that there is not a clear line defining the relationship of political scientists to the people, places, and contexts of where or how research is done. Desposato notes that political scientists may not always comply with regulations or the law but should have a reason for noncompliance. Pepinsky moves to accept the report; Goren seconds and the motion passes with two abstentions.

\section{DELEGATION OF AUTHORITY TO EXECUTIVE COMMITTEE DISCUSSION}

$\mathrm{McClain}$ introduces discussion of two resolutions regarding delegation of Council authority to the Executive Committee. S. Smith notes that under the bylaws adopted in 2016, the Executive Committee cannot act without specific delegation of authority from the Council. S. Smith notes that the proposed delegation of authority in the case of emergencies is not blanket authority but would only apply under certain, specified circumstances where waiting for an in-person Council meeting or time to get unanimous consent is not feasible. Williams asks if there is a provision for attempts to convene the full council to make emergency decisions and what would determine the attempts for full council to be impractical and infeasible. Super reports that the current bylaws provide for the Council to be called upon under short notice or for actions to be taken by APSA staff under good faith in certain circumstances. She notes there is a gap between an emergency circumstance and those that require full council. The proposed delegation of authority, according to Super, seeks to address that gap. McConaughey clarifies the circumstances under which an emergency action may be taken. R. Smith and Sinclair-Chapman express trust in the executive committee with the understanding that Council will be informed of Executive Committee actions. Leal expresses concern that informing full Council of Executive Committee discussions may take undue time. Carens expresses concern about how widely certain information, particularly those of confidential manner, may be shared. Goren, Sjoberg, and R. Smith agree that Council should be informed of all
Executive Committee actions with specific consideration given to confidentiality and timely notification of the Council. Goren moves to the amend the resolution to read, "The APSA Council will be immediately alerted to actions taken under this provision, and the APSA Executive Committee will fully report such actions to the Council at or before the subsequent Council meeting." Filindra seconds. The motion passes with one abstention. Williams moves to adopt the resolution as amended; motion is seconded and passes unanimously.

S. Smith introduces a second resolution with the purpose of delegating authority to the Executive Committee to act on Ethics Committee findings, recommendations, and sanctions. Garcia-Bedolla asks under what circumstances the Executive Committee may act, what the Executive Committee's role is, and what obligation the Executive Committee has to inform Council of actions taken. S. Smith replies that the Ethics Committee can make a recommendation on sanctions to the Executive Committee. Under the resolution, the Executive Committee would have the authority to act on behalf of the Council to implement, approve, or deny the sanction. Garcia-Bedolla recommends that Council be informed in a timely manner but that confidentiality be considered when sharing the information. Leal and GarciaBedolla inquire about the level of specificity with which Council will be informed of these decisions. Williams and Richards note that it may not make sense for Council to be immediately informed about some confidential matters. McClain notes that the extent to which information that can or should be shared with Council is based on circumstances as well as legality. R. Smith expresses concern about language around timing of informing Council being too specific and limiting appropriate discretion. Goren moves to amend the resolution to say, "The APSA Executive Committee will report such actions to the Council in an appropriate and timely manner." Motion is seconded and passes unanimously. A motion is made to adopt the resolution as amended; motion is seconded and passes unanimously.

\section{PERSPECTIVES EDITOR REVIEW COMMITTEE REPORT}

McClain introduces the Perspectives Editor Review Committee Report. She welcomes Wendy Pearlman, chair of the Perspectives Editor Review Committee. Pearlman 
reports that the editors are making many technical innovations and are lowering the desk rejection rate. The committee was enthusiastic about the innovations and improvements that the team has made. Pearlman notes several recommendations from the committee. First, that the editors and APSA Council should explore ways to increase the diversity and inclusion of the editorial team both now and in the future. Second, that the process for developing and choosing themes for special issues be made more transparent by introducing open calls for proposing themes for special issues. Overall, the Perspectives Editor Review Committee recommends that the editorial team's term be renewed. A motion is made to accept the report and renew the Perspectives editorial team for a two-year extension of their contract; the motion is seconded and passes with one abstention.

\section{PUBLICATIONS DISCUSSION}

McClain introduces a discussion on publishing. Jon Gurstelle, Director of Publishing, begins the discussion by noting that the pandemic has affected publications. Gurstelle reports that authors and members have increasingly noted the importance of open-access journals. He reports that many European funding agencies mandate that certain research be published in purely open-access journals. He notes that APSA has multiple options available to increase open-access offerings to members. The first option is to overlay an open-access journal with the APSA Preprints. The second option is to shift PS: Political Science $\mathcal{E}$ Politics to an open access model. The third option is to launch a new journal. Leal notes that a broader discussion regarding the value proposition and future of journals is important. Hamann notes that journals should reflect the disciple and who APSA serves, both members and society. Leal and Pepinsky note that a move to digital journals could permit a greater number of articles to be published. Ansell notes that there is an increasing trend of publishers not utilizing their full page budget. SinclairChapman expresses concern about striking the proper balance between competitive scarcity and more open publishing. Pepinsky notes that external circumstances may facilitate a transition to open access. He expresses a desire to launch a new, openaccess journal. Several Council members express concern about launching a new journal. Concerns include the needs of the discipline, branding, quality, cost-sharing, and logistical concerns. Filindra notes that some disciplines are moving toward instituting a processing fee, partially to manage the volume of submissions. McClain expresses concern about a processing fee. $\mathrm{S}$. Smith replies that a processing fee is not currently being discussed, but political science may eventually move in that direction. Berinsky and Garcia-Bedolla express concern about creating a new journal because of the potential that it be seen as an online, shadow version of an existing journal. Garcia-Bedolla notes that a digital format could provide new opportunities. Price suggests tailoring an openaccess journal toward a particular outreach function. Super reminds the Council of the possibility of making $P S$ open access and asks for specific recommendations. Carens and Williams express interest in making incremental changes that will allow certain latitude as the transition to open access occurs. Williams notes that incremental changes provide an opportunity to gain institutional experience and address financial and logistical concerns. S. Smith notes that a process of incremental changes would permit APSA to begin the process of adapting to an open access model before regulations mandate open access. Goren notes that an open access option may assist in increasing public engagement within the discipline. Filindra suggests that APSA launch a fund to support scholars that need to publish in an open-access journal.

Gurstelle introduces discussion of the possibility of launching an APSA magazine. He reports that the APSA magazine would consist of removing the Association section from $P S$ and making it a standalone member publication. He notes that an APSA magazine would allow more of $P S$ to be devoted to peer-reviewed, scholarly content, create a clear idea of the journal's impact factor, provide outlets for public engagement, and be a member benefit. Pepinsky notes that he enjoys the APSA magazine prototype that was shared, especially that it reads well in a digital format. Sinclair-Chapman asks about the role of the APSA magazine in public engagement and outreach compared to internal member usage.

Gurstelle introduces a discussion regarding print subscriptions for journals. He notes that Cambridge, due to the pandemic, has temporarily stopped printing journals. He notes that APSA provides free print subscription to members and absorbs the costs, which are approxi- mately \$80,ooo per year. Gurstelle notes that according to a recent member survey, only $11 \%$ of APSA members primarily access the journals in print. Sjoberg moves to end free print subscriptions for members. Goren seconds. McClain expresses concern about ending free print subscriptions without more time and research being done. Pepinsky, Williams, and Carens express concern about ending print subscription due to accessibility issues, the digital divide, and possible equity impacts without first addressing those concerns. Carens notes that the majority of those getting print journals are students, but he wants to use a nudge technique to move more students to an online format. Richards notes that Council previously voted to not end print subscriptions. She asks that issues of ending print subscriptions are addressed before voting to end them. Garcia-Bedolla suggests the Publications Committee comes to the fall Council meeting with a proposal that takes into account questions about who is receiving print journals as well as equity concerns of ending print subscriptions. The motion moves to a vote and fails with 7 ayes, 18 nays, and 2 abstentions.

\section{SMITH TASK FORCE REPORT}

McClain introduces the Smith Task Force Report and welcomes Robert Lieberman, chair of the Smith Presidential Task Force. Lieberman explains that the work of the task force was to explore what APSA could do to expand the reach and relevance of political science. He notes that the task force recommended programs and worked with APSA staff to implement and institutionalize those programs in three categories (civic engagement, teaching, and research), and that programs that are now underway in all three categories. McClain expresses her thanks to R. Smith, Lieberman, and the other task force members. Goren moves to accept the report; Williams seconds and the motion passes unanimously.

\section{INVESTMENT COMMITTEE RECOMMENDATIONS}

McClain introduces the investment committee's recommendations for an updated investment policy for Council approval. S. Smith reports that a policy was submitted to Council in fall 2019. The Council directed the Investment Committee to come back with a policy that included language and recommends regarding socially responsible/environmental, social, and governance (ESG) investing. Pepin- 
sky notes that given market conditions, he is glad APSA has a policy that will permit socially responsible investing that is also productive for the association. Bowman asks how the ESG investing portion of the investment policy will be implemented and evaluated. Pepinsky replies that the investment committee is working with the investment adviser to choose a range of investment vehicles that offer comparable returns to the market while maintaining social responsibility. He notes that the investment committee will evaluate the return on investment. S. Smith reports that fund will be incrementally moved to ESG funds in a slow and cautious manner. Goren moves to accept the invest committee's recommendations for an updated investment policy; Wedeen seconds and the motion passes with three abstentions.

\section{NEW AWARD PROPOSALS}

McClain introduces two new awards for Council discussion and approval. Sjoberg reports that the community college faculty award was recommended by the Committee on the Status of Community Colleges in the Profession. The Membership and Professional Development Committee then reviewed the proposal and suggested some edits. The purpose of the award is to recognize the contributions of community college faculty. Richards notes that the award is a good way to express to the membership and the public the value that APSA places on community college faculty. Hamann expresses concern about the specificity of what institutions may be able to apply. Sjoberg replies that the language is intentionally vague, and the award committee will decide if a nomination fits the spirit of the award. Richards moves to establish the Community College Faculty Award; Goren seconds and the motion passes unanimously.

Linn begins discussion of the proposal for a poster prize award for graduate students and junior faculty. She reports that the National Institute of Social Science (NISS) is sponsoring the award. She notes that the Meetings and Conference Committee reviewed the proposal and recommends approving the creation of the award with the understanding that the committee will continue working with APSA staff on the implementation plan. Sinclair-Chapman asks if more than one award can be given as well as what the role of Organized Sections will be in the award process. Linn replies that the proposal is suggesting that Orga- nizes Sections will nominate posters, but she notes that there are logistical concerns to work out. Marso expresses interest in awarding more than one prize due to varied subfields being presented. Kocher moves to establish the APSA/NISS poster prize; Filindra seconds and the motion passes with one abstention

\section{RELATED GROUP POLICY IMPLEMENTATION PLAN}

McClain introduces the Related Group Policy Implementation Plan. S. Smith notes that the Council previously voted to establish a new policy for related groups, including a minimum membership level and establishing bylaws for each related group. Goren asks if related groups have been resistant to the policy. McConaughey replies that some groups have reached out with questions about the new requirements but have not expressed resistance. Bowman asks about the impact of the implementation plan on the number of related groups. $\mathrm{S}$. Smith replies that the number of related groups will most likely decrease, for a variety of reasons. He notes that some current related groups will transition to being organized sections, some will develop memorandums of understanding with APSA, some will become institutional members, and some may cease their relationship with APSA. Goren moves to adopt the implementation plan; the motion is seconded and passes unanimously.

\section{ORGANIZED SECTIONS AND RELATED GROUP PROPOSALS}

McClain introduces proposals for two new organized sections and a new related group for Council discussion and approval. Sjoberg, chair of the Membership and Professional Development Committee reports that there are two proposals for organized sections, one for a Civic Engagement Organized Section and one for an Education Politics and Policy Organized Section. She explains that the Organized Section Committee has reviewed both proposals and recommends them for approval. Sjoberg and Bowman note that the impact of new sections on existing sections should be studied to inform future decisions about Organized Sections. Sjoberg moves to approve the Civic Engagement Organized Section; Goren seconds and the motion passes with one abstention. Sjoberg moves to approve the Education Politics and Policy organized section; Williams seconds and the motion passes with three abstentions. Linn, chair of the Meetings and Conferences Committee notes that there is also a proposal for a new related group, focused on Democratic Innovations. The committee has reviewed the proposal and supports its approval. Goren moves to approve the Democratic Innovations related group; the motion is seconded and passes with one abstention.

\section{ADVOCACY UPDATE}

McClain introduces a discussion of APSA's advocacy efforts to update Council. S. Smith discusses advocacy efforts relating to the rebranding plan at the National Science Foundation (NSF). NSF has added two programs initially intended to replace the political science program, called Accountable Institutions \& Behavior and Security \& Preparedness. In response to APSA advocacy efforts the political science program will also be preserved as a funding stream at NSF for a one-year transition period. APSA is working with congressional contacts to ensure data collection and evaluation of the new programs alongside the continuing political science program.

APSA has also developed a strategy to build long-term political support for political science. S. Smith reports that APSA hosted an Advocacy Day in March 2020 and met with several members of Congress. He notes that APSA is looking to create a bipartisan political science caucus. Super notes that this work is in addition to advocacy being done already in conjunction with cognate associations. Paulson notes that the advocacy groundwork and coalition building has allowed APSA to respond quickly to changes that affect political science. Leal asks if APSA is encouraging political scientists to meet with elected officials. Paulson replies that APSA is happy to organize meetings with elected officials, particularly congressional offices. Leal asks if APSA is utilizing the Congressional Fellowship Program alumni in advocacy efforts. S. Smith replies that it a great suggestion that could be part of the advocacy strategy going forward.

\section{POLICY COMMITTEE UPDATES}

Jordan-Zachery, chair of the Teaching and Learning Policy Committee, provides updates on the work of the committee. She reports that the committee is seeking more data about the impact of the Teaching and Learning Conference and TLC at APSA. Richards adds that the committee would like to see TLC at APSA continue for a few 
more years to gain more data on how to improve the conference. She reports that many community college faculty attend the stand-alone Teaching and Learning Conference, while the majority of persons who attend TLC at APSA are annual meeting attendees or are from the area in which the APSA annual meeting is held. Hamann notes that the format of the standalone Teaching and Learning Conference is not easily replicated at TLC at APSA. She notes that she would like to see how to increase community college, contingent, and adjunct faculty attendance at the TLC at APSA workshop. She notes that there is value in the stand-alone Teaching and Learning Conference as well.

Sinclair-Chapman, chair of the Public Engagement Committee, provides updates on the work of the committee. She notes that the committee is working on a report and recommendations regarding tenure and promotion policies that will be available in spring 2020.

Sjoberg, chair of the Membership and Professional Development Committee, provides updates on the work of the committee. She reports that the committee has worked to update information about APSA support for members affected by political travel bans on the APSA website. She continues that the committee has explored what membership and professional development may look like in a more virtual environment. Sjoberg reports that the Membership and Professional Development Committee has reviewed a proposal from President-Elect Janet Box-Steffensmeier and recommends the creation of an ad hoc career committee that may evolve into a standing committee. The purpose would be to work with institutions regarding best practices in employment of political scientists in academia, industry, government, and nonprofits. Leal, Hamann, and Box-Staffensmeir add their support for the ad hoc careers committee. Sjoberg introduces a motion to create an ad hoc careers committee; the motion is seconded and passes unanimously.

Linn, chair of the Meetings and Conferences committee, provides updates on the work of the committee. She notes that all committee updates were discussed previously in the meeting.

Leal, chair of the Publications Committee, provides updates on the work of the committee. He notes that all points were discussed previously in the meeting.

\section{NEW BUSINESS}

McClain calls for new business. Linn moves to create a presidential task force on the discipline's response to the coronavirus; Williams seconds and the motion passes unanimously. McClain and S. Smith present the Nominating Committee's slate of nominees. Richards expresses appreciation for the institutional diversity represented among the nominees. Goren asks about the role of the vice presidents within the Council structure. S. Smith replies that the role of the vice presidents was taken under consideration when the bylaws were reformed. He notes that the bylaws now mandate that vice presidents must previously have served on Council, which makes institutional diversity difficult for those positions due to the preponderance of former Council members that are employed at large research institutions. Hamann notes that the role of the vice presidents will be an ongoing discussion.

McClain adjourns the meeting. 